\title{
Effect of Oxygen Partial Pressure on the Electrical and Optical Properties of DC Magnetron Sputtered Amorphous $\mathrm{TiO}_{2}$ Films
}

\author{
M. Chandra Sekhar, ${ }^{1}$ P. Kondaiah, ${ }^{1}$ B. Radha Krishna, ${ }^{2}$ and S. Uthanna ${ }^{1}$ \\ ${ }^{1}$ Department of Physics, Sri Venkateswara University, Tirupati 517 502, India \\ ${ }^{2}$ PBR Visvodaya Institute of Technology and Sciences, Kavali 524 201, India
}

Correspondence should be addressed to S. Uthanna; uthanna@rediffmail.com

Received 10 June 2012; Accepted 16 September 2012

Academic Editor: Niksa Krstulovic

Copyright (C) 2013 M. Chandra Sekhar et al. This is an open access article distributed under the Creative Commons Attribution License, which permits unrestricted use, distribution, and reproduction in any medium, provided the original work is properly cited.

\begin{abstract}
Titanium dioxide $\left(\mathrm{TiO}_{2}\right)$ thin films were deposited on $\mathrm{p}$-Si (100) and Corning glass substrates held at room temperature by DC magnetron sputtering at different oxygen partial pressures in the range $9 \times 10^{-3}-9 \times 10^{-2} \mathrm{~Pa}$. The influence of oxygen partial pressure on the structural, electrical, and optical properties of the deposited films was systematically studied. XPS studies confirmed that the film formed at an oxygen partial pressure of $6 \times 10^{-2} \mathrm{~Pa}$ was nearly stoichiometric. $\mathrm{TiO}_{2}$ films formed at all oxygen partial pressures were X-ray amorphous. The optical transmittance gradually increased and the absorption edge shifted towards shorter wavelengths with the increase of oxygen partial pressure. Thin film capacitors with configuration of $\mathrm{Al} / \mathrm{TiO}_{2} / \mathrm{p}$-Si have been fabricated. The results showed that the leakage current density of films formed decreased with the increase of oxygen partial pressure to $6 \times 10^{-2} \mathrm{~Pa}$ owing to the decrease in the oxygen defects in the films thereafter it was increased. The current transport mechanism in the $\mathrm{TiO}_{2}$ thin films is shown to be Schottky effect and Fowler-Nordheim tunnelling currents.
\end{abstract}

\section{Introduction}

Titanium dioxide $\left(\mathrm{TiO}_{2}\right)$ thin films are widely used because of their remarkable electrical and optical properties. $\mathrm{TiO}_{2}$ can be used as an alternative dielectric to silicon dioxide films in ultra-large-scale integration due to its much higher dielectric constant [1], lower leakage current, and higher breakdown strength than that of $\mathrm{SiO}_{2}$ [2]. $\mathrm{TiO}_{2}$ thin films have attracted considerable attention for applications in photocatalysts and solar cells [3]. These films also exhibit a large potential in the fields such as protective antireflection coatings [4], gas sensors [5], and air purification [6]. $\mathrm{TiO}_{2}$ films were prepared by numerous deposition techniques such as metal organic chemical vapour deposition, spray pyrolysis, solgel process, thermal oxidation, pulsed laser deposition, and reactive magnetron sputtering [7-10]. However, the electrical properties of the oxide layer are affected by the growth technique due to reactions at the oxide/Si substrate interface [11]. Among these techniques, magnetron sputtering method provides more advantage in controlling the microstructure and composition of the films. The structural and electrical properties are known to be easily affected by the deposition conditions such as the substrate temperature, substrate bias voltage, and oxygen partial pressure as well as the postdeposition annealing. The effect of substrate temperature [12] and substrate bias voltage [13] on the structural, electrical, and dielectric properties of magnetron sputtered $\mathrm{TiO}_{2}$ films was reported. In this investigation, the influence of oxygen partial pressure on the structural and electrical behavior of DC magnetron sputtered $\mathrm{TiO}_{2}$ thin films was studied.

\section{Experimental}

2.1. Thin Film Preparation. Thin films of $\mathrm{TiO}_{2}$ were deposited on RCA-cleaned and HF-treated, low-resistivity $(0.01-0.02 \Omega \mathrm{cm})$ p-type silicon (100) and Corning glass substrates by DC reactive magnetron sputtering technique. Pure titanium target of $100 \mathrm{~mm}$ diameter and $3 \mathrm{~mm}$ thick was used as sputter target. The vacuum pumping system employed for sputtering was a combination of diffusion and rotary pumps. Pure oxygen and argon were used as reactive and sputtering gases, respectively. After achieving ultimate pressure of $2 \times 10^{-4} \mathrm{~Pa}$, the fixed quantities of 


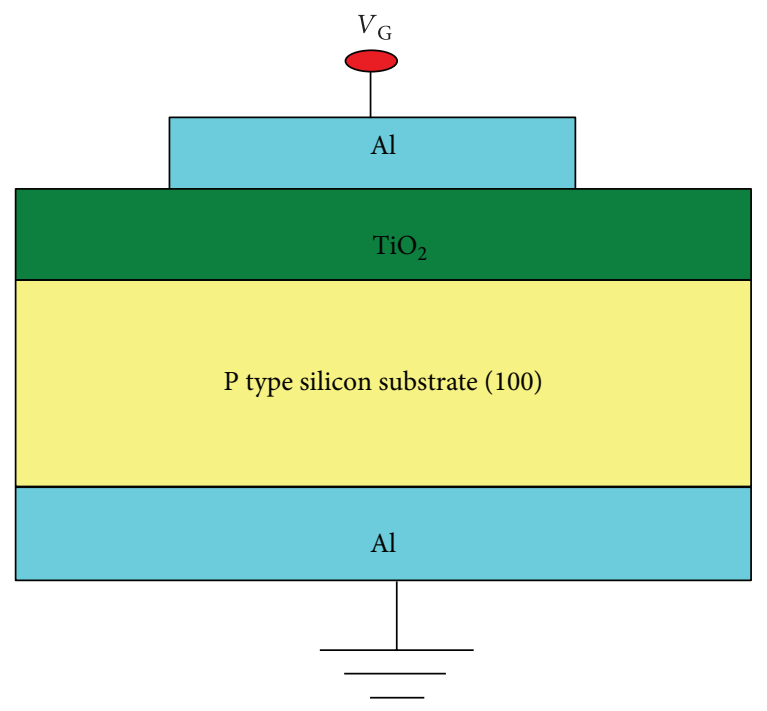

FIGURE 1: Sample configuration for electrical measurement.

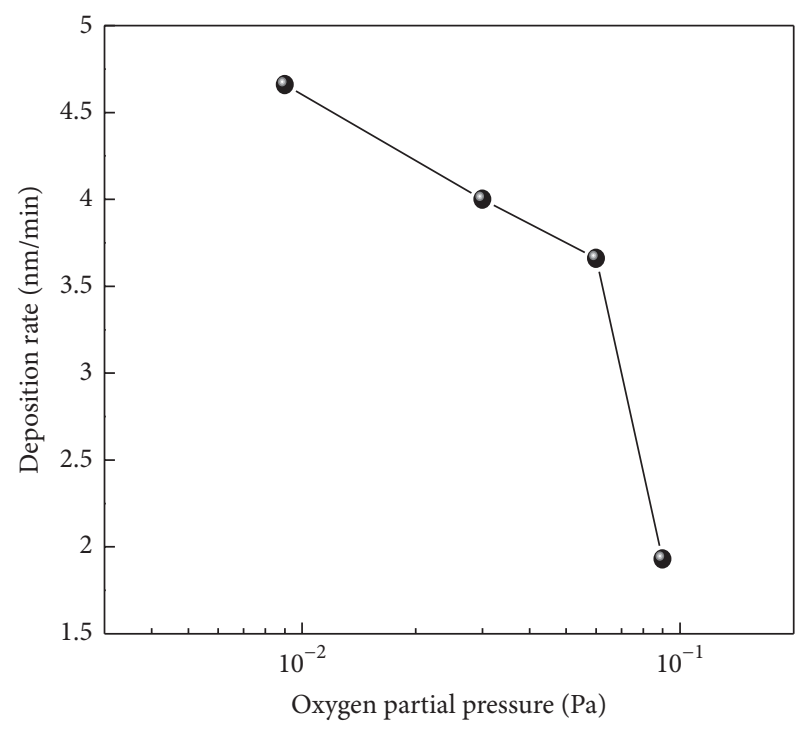

FIgURE 2: Variation of deposition rate of $\mathrm{TiO}_{2}$ films with oxygen partial pressure.

oxygen and argon gases were admitted into the sputter chamber through the flow controlled needle valves and their flow rates were monitored individually employing Aalborg mass flow controllers. The $\mathrm{TiO}_{2}$ films were deposited at different oxygen partial pressures by fixing the other process parameters kept constant. The deposition conditions maintained during the growth of the $\mathrm{TiO}_{2}$ films are given in Table 1. In order to fabricate metal-oxide-semiconductor structure, $\mathrm{TiO}_{2}$ layer was formed on the p-Si (100) wafers. Aluminium top contacts were formed by sputtering using shadow masks over the oxide layer with fixed area of $9 \times$ $10^{-4} \mathrm{~cm}^{2}$. The back contacts of thick Al layer, which was deposited by sputtering. High doping in Si ensured that the back contacts were ohmic. The sample configurations for metal insulator-semiconductor for electrical measurements are shown in Figure 1.
TABLE 1: Deposition conditions maintained during the preparation of $\mathrm{TiO}_{2}$ films.

\begin{tabular}{ll}
\hline Sputter target & Titanium target $(99.9 \%$ pure $)$ \\
Target to substrate distance & $80 \mathrm{~mm}$ \\
Ultimate pressure & $2 \times 10^{-4} \mathrm{~Pa}$ \\
Oxygen partial pressure & $9 \times 10^{-3}-9 \times 10^{-2} \mathrm{~Pa}$ \\
Sputter pressure & $0.5 \mathrm{~Pa}$ \\
Substrate temperature & $303 \mathrm{~K}$ \\
Sputter power & $200 \mathrm{~W}$ \\
\hline
\end{tabular}

2.2. Thin Film Characterization. The X-ray photoelectron spectroscopic (XPS) studies were performed to analyze the core level binding energies by using SPECS GmbH spectrometer (Phoibos $100 \mathrm{MCD}$ Energy Analyzer) with $\mathrm{MgK}_{\alpha 1}$ radiation $(1253.6 \mathrm{eV})$. The chemical binding configuration, structural properties of $\mathrm{TiO}_{2}$ thin films were determined using Raman spectra recorded at room temperature using Jobin Yvon (Model HR $800 \mathrm{UV}$ ) Raman spectrometer in the wavenumber range $100-1000 \mathrm{~cm}^{-1}$. X-ray diffractometer (Seifert model $3003 \mathrm{TT})$ with $\mathrm{CuK}_{\alpha 1}$ radiation $(\lambda=$ $0.15405 \mathrm{~nm}$ ) was used to analyze the crystallographic structure of the films formed on silicon substrates. The physical thickness of the films was measured by using $\alpha$-step profilometer. The optical transmittance of the films formed on Corning glass substrates was recorded by using UV-VisNIR double beam spectrophotometer (Perkin Elmer model Lambda 950) in the wavelength range $300-1500 \mathrm{~nm}$. The electrical properties of the $\mathrm{TiO}_{2}$ thin films were evaluated by current-voltage (I-V) measurements. The test samples with metal-insulator-semiconductor (MIS) capacitor structures were prepared on p-type Si (100) substrates. Aluminum electrodes were prepared by using DC reactive magnetron sputtering. The current-voltage characteristics of the $\mathrm{Al} / \mathrm{TiO}_{2} / \mathrm{p}-\mathrm{Si}$ capacitors were measured by using Hewlett Packard (model hp 4140 B) pA meter.

\section{Results and Discussion}

3.1. Structural Properties. Figure 2 shows the dependence of deposition rate of $\mathrm{TiO}_{2}$ films on the oxygen partial pressure. The deposition rate of the films formed at low oxygen partial pressure of $9 \times 10^{-3} \mathrm{~Pa}$ was $4.6 \mathrm{~nm} / \mathrm{min}$. The deposition rate of the films is decreased to $1.9 \mathrm{~nm} / \mathrm{min}$ at an oxygen partial pressure of $9 \times 10^{-2} \mathrm{~Pa}$. The high deposition rate at low oxygen partial pressure was due to the high sputtering yield of metallic titanium and insufficient oxygen present in the sputter chamber. The decrease of deposition rate at higher oxygen partial pressure was related to the chemical reaction between the target surface and the reactive gas of oxygen. This led to the formation of oxide layer on the target surface and in turn reduces in the deposition rate [14]. Jagadeesh Chandra et al. [15] also observed the decrease of films thickness with the increase of oxygen partial pressure in RF magnetron sputtered $\mathrm{Ta}_{2} \mathrm{O}_{5}$ films.

Figure 3 shows the XPS survey spectra of $\mathrm{TiO}_{2}$ thin films formed at different oxygen partial pressures. The survey 


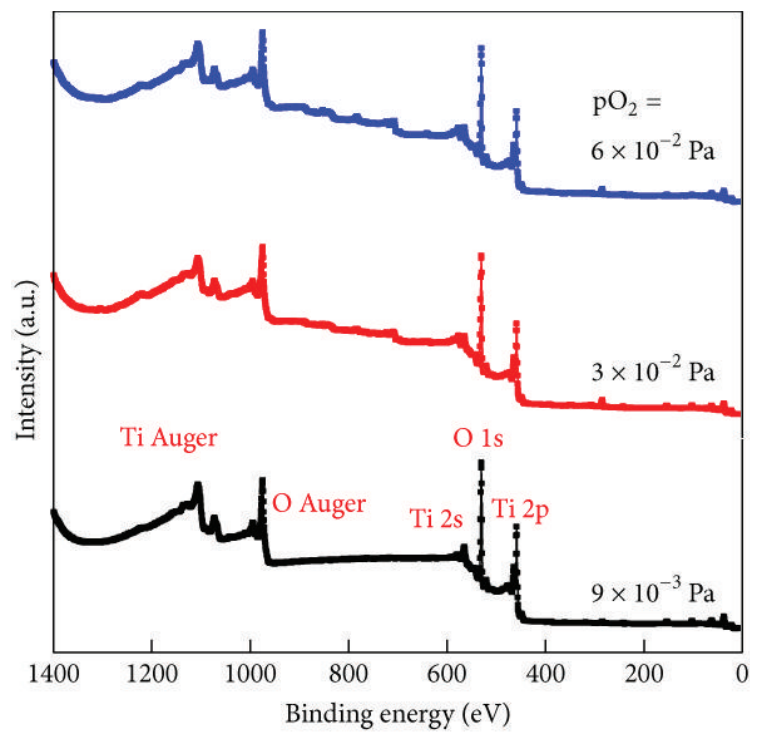

FIGURE 3: XPS survey scan spectra of $\mathrm{TiO}_{2}$ films formed at different oxygen partial pressures.

spectra show the characteristic of titanium, oxygen, and carbon peaks. A carbon 1s peak was observed at a binding energy of $284.4 \mathrm{eV}$ on all samples before ion bombardment. The presence of this peak is related to organic surface contamination, which corresponds to the fact that the samples are exposed to air before measurements. The carbon peak disappeared from the surface of $\mathrm{TiO}_{2}$ films after presputtering with argon ion bombardment.

Figure 4(a) shows the narrow scan spectra of Ti $2 p$ in $\mathrm{TiO}_{2}$ films formed at different oxygen partial pressures in the range $9 \times 10^{-3}-6 \times 10^{-2} \mathrm{~Pa}$. The Ti $2 \mathrm{p}$ signal is associated with two peaks which are representative for $\mathrm{Ti} 2 \mathrm{p}_{3 / 2}$ to $\mathrm{Ti}$ $2 p_{1 / 2}$ spin-orbital splitting. The films formed at $9 \times 10^{-3} \mathrm{~Pa}$ showed the core level binding energies of $\mathrm{Ti} 2 \mathrm{p}_{3 / 2}$ and $\mathrm{Ti}$ $2 \mathrm{p}_{1 / 2}$ is 457.2 and $462.7 \mathrm{eV}$ (energy separation of $5.5 \mathrm{eV}$ ). The core level binding energies of the films formed at $6 \times$ $10^{-2} \mathrm{~Pa}$ shifted to 458.2 and $463.9 \mathrm{eV}$ (energy separation of $5.7 \mathrm{eV}$ ) which indicated the presence of $\mathrm{Ti}^{4+}$ oxidation state in $\mathrm{TiO}_{2}$. Liu et al. [16] reported the core level binding energies of Ti $2 \mathrm{p}$ with two peaks located at 458.1 and $463.7 \mathrm{eV}$ for Ti $2 \mathrm{p}_{3 / 2}$ and Ti $2 \mathrm{p}_{1 / 2}$ with energy separation of $5.6 \mathrm{eV}$. Figure 4(b) showed the narrow scan spectra of $\mathrm{O} 1 \mathrm{~s}$ at different oxygen partial pressures. The core level binding energy of $\mathrm{O}$ 1s peak shifted from 529.7 to $530.5 \mathrm{eV}$ with increase of oxygen partial pressure from $9 \times 10^{-3}$ to $6 \times 10^{-2} \mathrm{~Pa}$, respectively. The chemical composition of the deposited films was determined from the area under the peak using the sensitivity factors $(\mathrm{C} 1 \mathrm{~s}=0.25$, Ti $2 \mathrm{p}=1.8$, and $\mathrm{O} 1 \mathrm{~s}=0.66)$. The films deposited at $6 \times 10^{-2} \mathrm{~Pa}$ showed the ratio of oxygen to titanium, that is, $\mathrm{O} / \mathrm{Ti}=1.97$, which indicated the growth of nearly stoichiometric films [17].

Figure 5 shows the X-ray diffraction profiles of the $\mathrm{TiO}_{2}$ thin films deposited at different oxygen partial pressures. It can be seen that all the films have not shown any diffraction peaks indicating the films were amorphous in nature. The

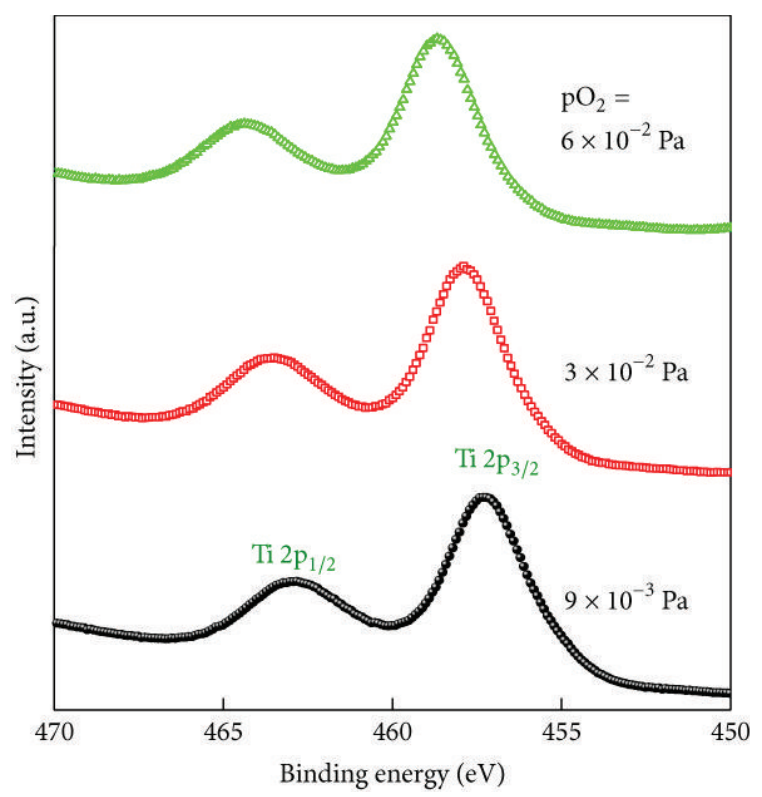

(a)

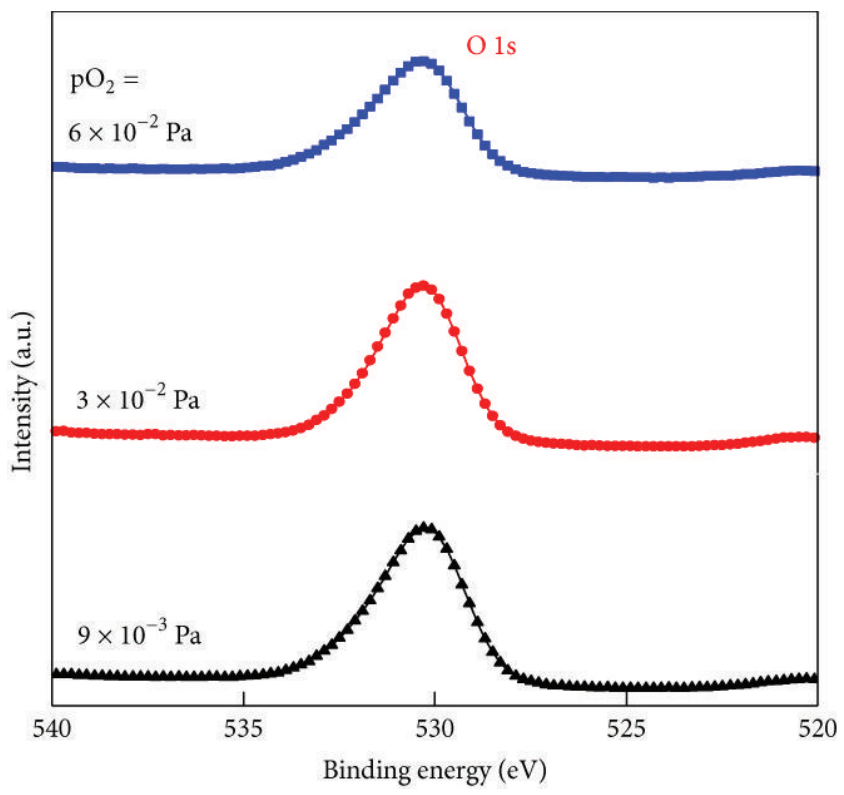

(b)

Figure 4: XPS narrow scan spectra of $\mathrm{TiO}_{2}$ films: (a) Ti 2p and (b) O 1 s.

amorphous structure of $\mathrm{TiO}_{2}$ thin films can be attributed to low surface mobility of deposition particles [18].

Anatase has a space group $\mathrm{D}_{4 \mathrm{~h}}\left(\mathrm{I}_{1} / \mathrm{amd}\right)$ containing two formula units per primitive unit cell. From the group analysis, there are six Raman active modes, $A_{1 g}+2 B_{1 g}+3 E_{g}$ and three infrared active modes, $A_{2 u}+2 E_{u}$. The Raman spectra for anatase single crystal were investigated by Ohsaka [19] who noticed six allowed bands in the first order Raman spectra were identified at $144 \mathrm{~cm}^{-1}\left(E_{g}\right), 197 \mathrm{~cm}^{-1}\left(E_{g}\right), 399 \mathrm{~cm}^{-1}$ $\left(B_{1 g}\right), 513 \mathrm{~cm}^{-1}\left(A_{1 g}\right), 519 \mathrm{~cm}^{-1}\left(B_{1 g}\right)$, and $639 \mathrm{~cm}^{-1}\left(E_{g}\right)$. The Raman spectra for the as-prepared $\mathrm{TiO}_{2}$ thin films at 


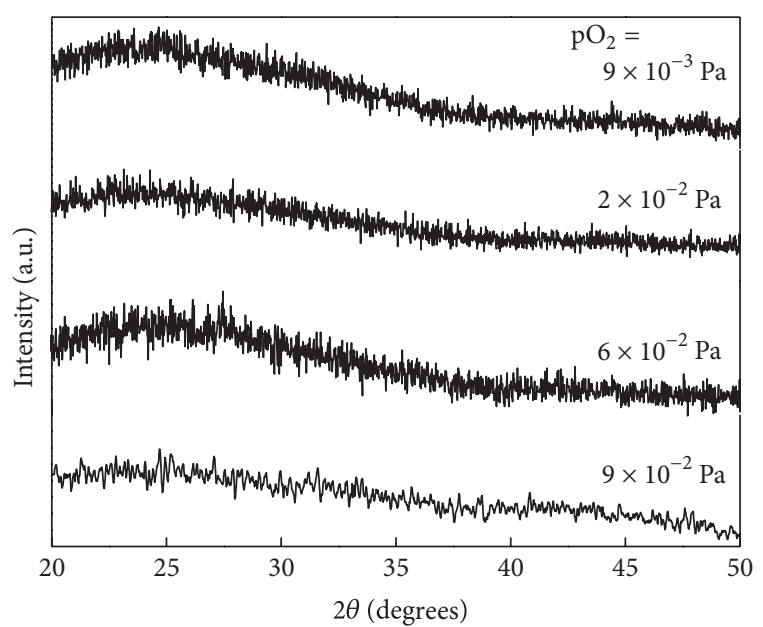

FIGURE 5: X-ray diffraction profiles of $\mathrm{TiO}_{2}$ films formed at different oxygen partial pressures.

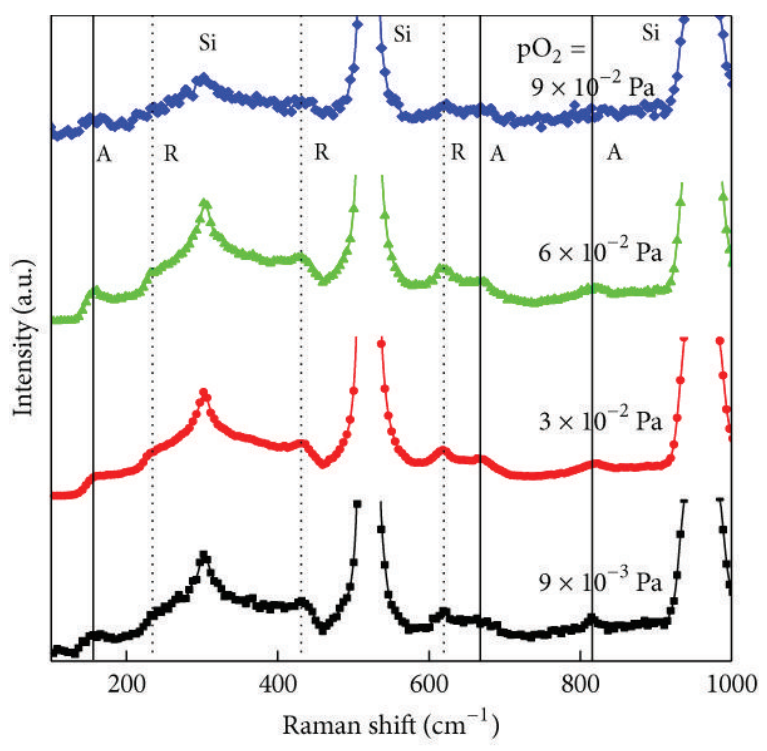

FIgURE 6: Raman spectra of $\mathrm{TiO}_{2}$ films formed at different oxygen partial pressures.

different oxygen partial pressures were shown in Figure 6. Raman peaks seen at $153,516,659$, and $810 \mathrm{~cm}^{-1}$ are assigned as $B_{1 g}(v 6), A_{1 g}+B_{1 g}(v 2+v 3), E_{g}(v 1)$, and $B_{1 g}$ Ti-O modes related to the anatase phase [20]. It is noted that the Raman peaks at $302 \mathrm{~cm}^{-1}$ and $520 \mathrm{~cm}^{-1}$ appeared from Si-Si bonding mode of the Si substrate. The Raman peaks at $516 \mathrm{~cm}^{-1}$ were not present because the intensity of $\mathrm{Si}$ dominates the intensity of $B_{1 g}$ doublet peaks. The Raman peaks at 233, 430, and $620 \mathrm{~cm}^{-1}$ related to the rutile phase [21]. It is seen that the peak at $153 \mathrm{~cm}^{-1}$ ( $E_{g}$ mode) strengthens, with increase in oxygen partial pressure from $9 \times 10^{-3}$ to $6 \times 10^{-2} \mathrm{~Pa}$, thereafter it weakens with the oxygen partial pressure up to $9 \times 10^{-2} \mathrm{~Pa}$ due to the reduction of film thickness. The rutile peak intensity was also decreased with increasing oxygen flow ratio as well as film thickness.

3.2. Optical Properties. The optical transmittance spectra of the $\mathrm{TiO}_{2}$ films formed at different oxygen partial pressures are shown in Figure 7. Obviously, the optical transmittance is high in the visible region and it increased with the increase of oxygen partial pressure from $9 \times 10^{-3}$ to $9 \times 10^{-2} \mathrm{~Pa}$, respectively. The optical transmittance of the films formed at low oxygen partial pressure of $9 \times 10^{-3} \mathrm{~Pa}$ was low maybe due to the formation of nonstoichiometric $\mathrm{TiO}_{2}$ films. As the oxygen partial pressure increased to $6 \times 10^{-2} \mathrm{~Pa}$, the adequate oxygen can repair the oxygen vacancies and hence increase the transmittance. The relation between the absorption coefficient and concentration of free carriers can be written as [22]

$$
\alpha=\frac{\mathrm{Ne}^{2} \lambda_{\mathrm{o}}^{2}}{8 \varepsilon_{\mathrm{o}} \pi \Gamma m^{*} n c^{3}},
$$

where $\alpha$ is the absorption coefficient, $\mathrm{N}$ the concentration of free carriers, $n$ the refractive index, $m^{*}$ the effective mass of free carrier, and $\lambda_{\mathrm{o}}$ the absorption wavelength. Equation (1) shows that the absorption coefficient of $\mathrm{TiO}_{2}$ films is directly proportional to the concentration of free carrier, namely, twofold concentration of oxygen vacancies. Hence, the substoichiometry of the $\mathrm{TiO}_{2}$ films induced by insufficient oxygen content is the main cause of transmittance differences. The transmittance of $\mathrm{TiO}_{2}$ thin films deposited at $9 \times 10^{-3} \mathrm{~Pa}$ is low, which indicated that the films have more oxygen vacancies. As the oxygen partial pressure increased to $6 \times 10^{-2} \mathrm{~Pa}$, the transmittance of the films increased since the oxygen ion vacancies tend to decrease and hence the composition of the films approached to the stoichiometric $\mathrm{TiO}_{2}$. Heo et al. [23] also observed the increase in optical transmittance with the increase of oxygen flow by RF magnetron sputtering method. The optical absorption edge of the films shifted markedly towards lower wavelengths side with the increase of oxygen partial pressure. The optical absorption coefficient $(\alpha)$ of the films was evaluated from the optical transmittance $(T)$ and reflectance $(R)$ data using the relation

$$
\alpha=\left(\frac{1}{t}\right) \ln \left[\frac{T}{(1-R)^{2}}\right],
$$

where $t$ is the thickness of the film. The optical band gap $\left(E_{g}\right)$ of the films was estimated from the intercept of the plots of $(\alpha h v)^{2}$ versus photon energy $(h v)$ which assumes the direct transition between the top of the valance band and the bottom of the conduction band using the relation

$$
(\alpha h v)=A\left(h v-E_{g}\right)^{1 / 2},
$$

where $A$ is the optical absorption edge width parameter. The optical band gap of the films increased from 3.45 to $3.60 \mathrm{eV}$ with the increase of oxygen partial pressure from 9 $\times 10^{-3}$ to $9 \times 10^{-2} \mathrm{~Pa}$. The low value of optical band gap of the films formed at low oxygen partial pressure was due 


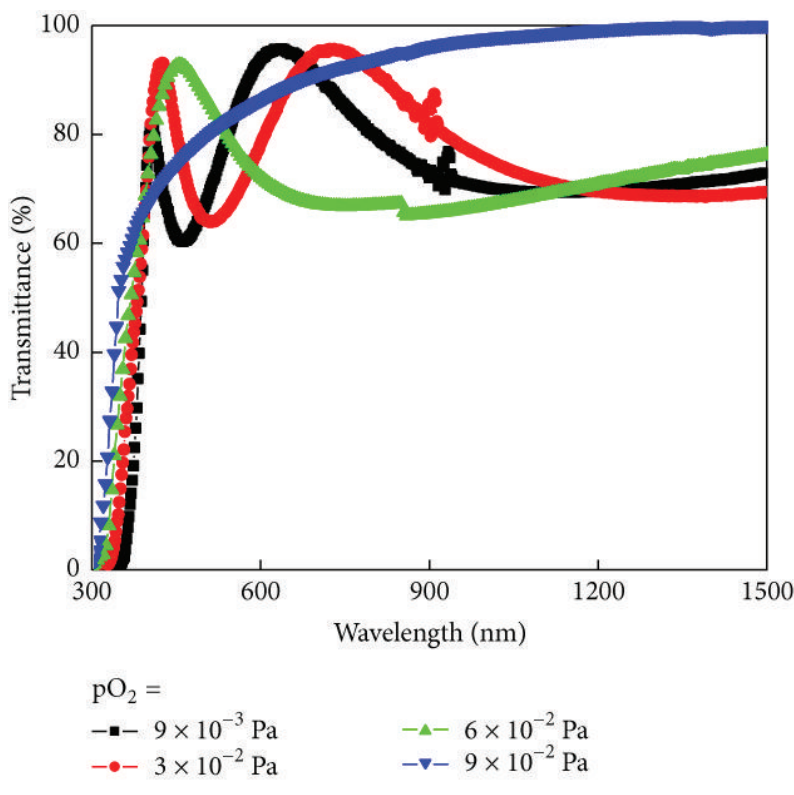

Figure 7: Optical transmittance spectra of $\mathrm{TiO}_{2}$ films formed at different oxygen partial pressures.

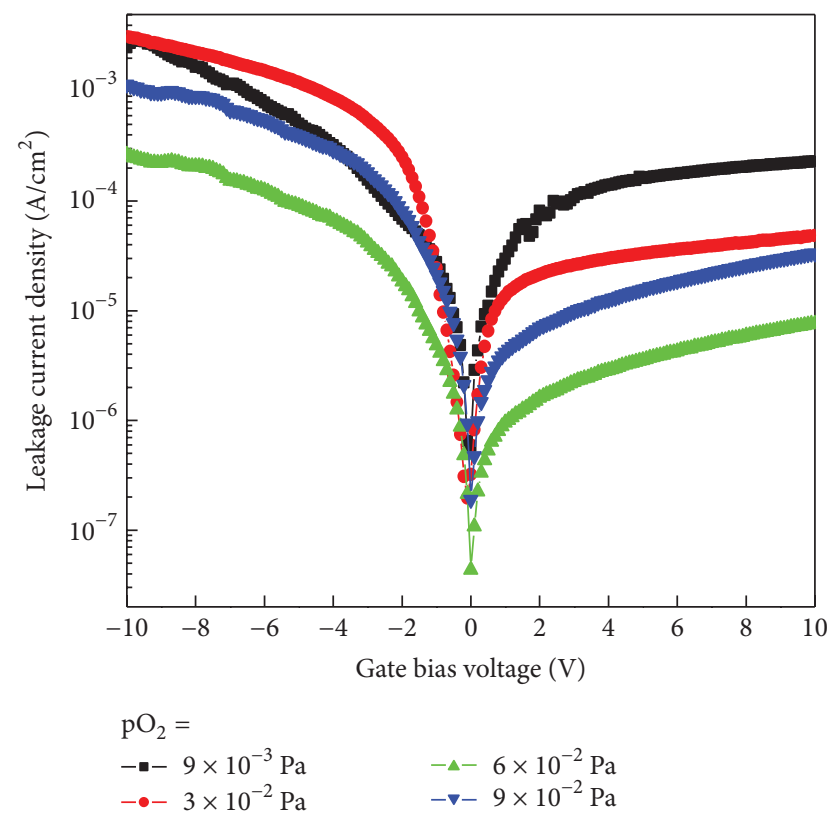

Figure 8: Current-voltage characteristics of $\mathrm{Al} / \mathrm{TiO}_{2} / \mathrm{p}$-Si capacitors.

to the formation of nonstoichiometric films. In the present investigation, the stoichiometric films deposited at an oxygen partial pressure of $6 \times 10^{-2} \mathrm{~Pa}$ showed an optical band gap of $3.50 \mathrm{eV}$.

3.3. Electrical Properties. Figure 8 shows the leakage current density versus applied voltage characteristics of the $\mathrm{Al} / \mathrm{TiO}_{2} / \mathrm{p}-\mathrm{Si}$ capacitors. The leakage current density $(J)$ measured at applied voltage $\mathrm{V}=1.5 \mathrm{~V}$ was decreased from $6.1 \times 10^{-5}$ to $1.3 \times 10^{-6} \mathrm{~A} / \mathrm{cm}^{2}$ with the increase of oxygen partial pressure from $9 \times 10^{-3}$ to $6 \times 10^{-2} \mathrm{~Pa}$. At higher oxygen partial pressure of $9 \times 10^{-2} \mathrm{~Pa}$, the leakage current density was increased to $5.5 \times 10^{-6} \mathrm{~A} / \mathrm{cm}^{2}[15,24]$. The increase in leakage currents at higher oxygen partial pressures was due to the decrease in film thickness. To validate the current transport mechanism through the $\mathrm{Al} / \mathrm{TiO}_{2} / \mathrm{p}$-Si capacitors, two main conduction mechanisms were examined. At low electric fields, the current density was proportional to the square root of the applied electric field (Schottky emission), while at higher electric fields it may be the possibility of Fowler-Nordheim conduction mechanism that was observed. The Schottky emission is given by the relation [17]

$$
J_{\mathrm{SE}}=A^{*} \mathrm{~T}^{2} \exp \left\{\frac{-1}{\mathrm{kT}\left(q \Phi-\beta_{\mathrm{SE}} \sqrt{E}\right)}\right\},
$$

where $A^{*}$ is the effective Richardson constant, $\Phi$ the Schottky barrier height $q$ the electronic charge, $k$ the Boltzmann constant, $E$ the electric field, and $h$ the Planck's constant. The constant $\beta_{\mathrm{SE}}$ is given by the relation

$$
\beta_{\mathrm{SE}}=\left(\frac{q^{3}}{4 \pi \varepsilon_{0} \varepsilon_{r}}\right)^{1 / 2},
$$

where $\varepsilon_{0}$ is the permittivity of free space and $\varepsilon_{r}$ the dielectric constant of the insulator. At higher bias voltages, the FowlerNordheim tunnelling of electrons through the triangular barrier to the conduction band of oxide will occur. The Fowler-Nordheim tunnelling current $J_{\mathrm{FN}}$ can be expressed as a function of the electric field in the gate oxide by the relation

$$
J_{\mathrm{FN}}=A E^{2} \exp \left[-\frac{B}{E}\right] \text {, }
$$

where $A=q^{2} / 8 \pi h \phi_{B}$ and $B=\left(8 \pi \sqrt{2 q m^{*}} / 3 h\right) \phi_{B}{ }^{3 / 2}$ are constants depending on $m^{*}$ and barrier height. $m^{*}$, the electron effective mass in dielectric layer which is $m^{*}=$ $0.3 m_{0}$ where $m_{0}$ is the free-electron mass [25].

Figure 9 shows $\ln (J)$ versus $E^{1 / 2}$ plots of the $\mathrm{Al} / \mathrm{TiO}_{2} / \mathrm{p}$ Si capacitors formed at different oxygen partial pressures in the range $9 \times 10^{-3}-9 \times 10^{-2} \mathrm{~Pa}$ with the applied positive bias voltage from $0 \mathrm{~V}$ to $+10 \mathrm{~V}$. Schottky emission follows at the interface between the $\mathrm{TiO}_{2}$ films and the aluminum electrode where a Schottky barrier is formed. This effect was attributed to the absorption current due to the dielectric relaxation phenomenon of the $\mathrm{TiO}_{2}$ capacitors. The plot ln $(J)$ versus $E^{1 / 2}$ showed a linear relationship with the applied electric field. This result indicates the I-V characteristics of $\mathrm{TiO}_{2}$ capacitors can be explained by Schottky emission in lower electric field region.

Figure 10 shows $\ln \left(J / E^{2}\right)$ versus $E^{1 / 2}$ (Fowler-Nordheim) plots of $\mathrm{Al} / \mathrm{TiO}_{2} / \mathrm{p}$-Si capacitors at positive substrate bias. It is noted that there are two significant regimes shown in the Fowler-Nordheim plot. At low electric fields, Schottky emission is the dominant current transport mechanism, as shown by the leakage current density versus applied gate voltage. At higher electric fields, Fowler-Nordheim tunnelling was observed. 


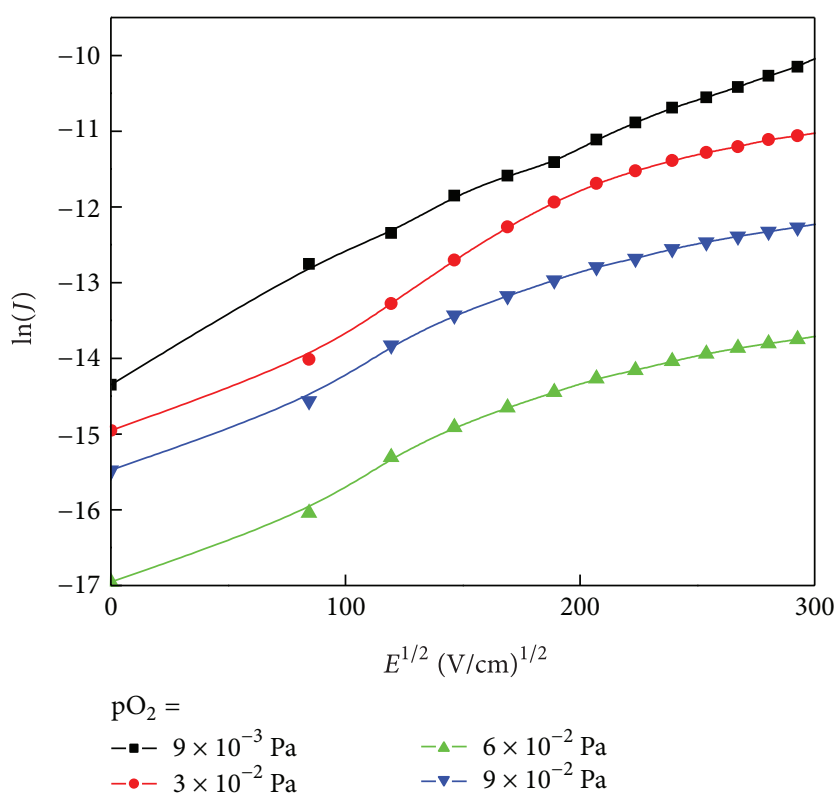

FIgURE 9: Schottky plots of $\ln (J)$ versus $E^{1 / 2}$ of $\mathrm{Al} / \mathrm{TiO}_{2} / \mathrm{p}-\mathrm{Si}$ capacitors.

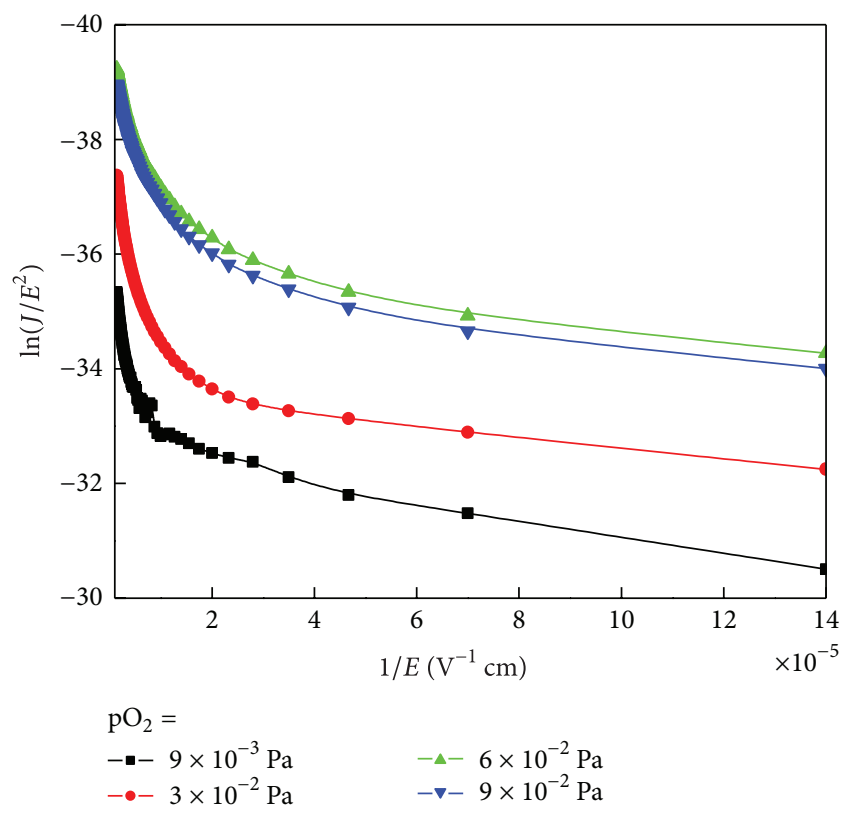

FIGURE 10: Fowler-Nordheim plots of $\ln \left(J / E^{2}\right)$ versus $E^{1 / 2}$ of $\mathrm{Al} / \mathrm{TiO}_{2} / \mathrm{p}$-Si capacitors.

\section{Conclusions}

Titanium oxide thin films were formed on glass and $\mathrm{p}$-silicon (100) substrates deposited by DC magnetron sputtering method under various oxygen partial pressures in the range $9 \times 10^{-3}-9 \times 10^{-2} \mathrm{~Pa}$. The deposition rate of the films was correlated with the oxygen partial pressure. From XPS studies it was confirmed that the films formed at an oxyen partial pressure of $6 \times 10^{-2} \mathrm{~Pa}$ were nearly stoichiometric. X-ray diffraction studies indicated the films deposited at all oxygen partial pressure were amorphous. The optical transmittance of the films was increased with the increase of oxygen partial pressure; the transmittance edge shifted towards the lower wavelength side. This may be ascribed to the decrease of oxygen vacancies as the increase of oxygen partial pressure. The optical band gap of the films increased from 3.45 to $3.60 \mathrm{eV}$ with the increase of oxygen partial pressure from $9 \times 10^{-3}$ to $9 \times 10^{-2} \mathrm{~Pa}$, respectively. Thin film capacitors with configuration of $\mathrm{Al} / \mathrm{TiO}_{2} / \mathrm{p}$-Si have been fabricated. The leakage current density of the films formed at low oxygen partial pressure of $9 \times 10^{-3} \mathrm{~Pa}$ was $6.1 \times 10^{-5} \mathrm{~A} / \mathrm{cm}^{2}$ and it was decreased to $1.3 \times 10^{-6} \mathrm{~A} / \mathrm{cm}^{2}$ with the increase of oxygen partial pressure to $6 \times 10^{-2} \mathrm{~Pa}$ and thereafter it was increased to $5.5 \times 10^{-6} \mathrm{~A} / \mathrm{cm}^{2}$. The leakage current is found to be dominated by the Schottky emission at low electric field, whereas Fowler-Nordheim tunnelling currents appear at higher electric fields.

\section{Acknowledgment}

This work was carried out with the financial support of University Grant Commission, New Delhi, through a sanctioned Major Research Project: F. No. 34-36/2008 (SR) dated 3012- 2008. One of the authors, M. Sekhar, is thankful to the University Grants Commission, New Delhi, for the award of UGC-RFSMS fellowship.

\section{References}

[1] S. Kundu, S. K. Roy, and P. Banerji, "GaAs metal-oxidesemiconductor device with titanium dioxide as dielectric layer: effect of oxide thickness on the device performance," Journal of Physics D, vol. 44, no. 15, Article ID 155104, 2011.

[2] W. Yang and C. A. Wolden, "Plasma-enhanced chemical vapor deposition of $\mathrm{TiO}_{2}$ thin films for dielectric applications," Thin Solid Films, vol. 515, no. 4, pp. 1708-1713, 2006.

[3] A. R. Armstrong, G. Armstrong, J. Canales, R. García, and P. G. Bruce, "Lithium-ion intercalation into $\mathrm{TiO}_{2}-\mathrm{B}$ nanowires," Advanced Materials, vol. 17, no. 7, pp. 862-865, 2005.

[4] C. J. Chung, H. I. Lin, and J. L. He, "Antimicrobial efficacy of photocatalytic $\mathrm{TiO}_{2}$ coatings prepared by arc ion plating," Surface and Coatings Technology, vol. 202, no. 4-7, pp. 1302-1307, 2007.

[5] B. Klimesz, G. Dominiak-Dzik, R. Lisiecki, and W. RybaRomanowski, "Systematic study of spectroscopic properties and thermal stability of lead germanate glass doped with rare-earth ions," Journal of Non-Crystalline Solids, vol. 354, no. 2-9, pp. 515-520, 2008.

[6] C. M. Maghanga, J. Jensen, G. A. Niklasson, C. G. Granqvist, and M. Mwamburi, "Transparent and conducting $\mathrm{TiO}_{2}: \mathrm{Nb}$ films made by sputter deposition: application to spectrally selective solar reflectors," Solar Energy Materials and Solar Cells, vol. 94, no. 1, pp. 75-79, 2010.

[7] A. B. Ravi Kumar, S. Uthanna, B. Srinivasulu Naidu, and P. Sreedhara Reddy, "Effect of oxygen partial pressure on the 
optical properties of DC magnetron sputtered $\mathrm{TiO}_{2}$ films," Journal of the Indian Institute of Science, vol. 81, no. 5, pp. 573-577, 2001.

[8] B. Karunagaran, R. T. Rajendra Kumar, V. Senthil Kumar, D. Mangalaraj, S. K. Narayandass, and G. Mohan Rao, "Structural characterization of DC magnetron-sputtered $\mathrm{TiO}_{2}$ thin films using XRD and Raman scattering studies," Materials Science in Semiconductor Processing, vol. 6, no. 5-6, pp. 547-550, 2003.

[9] D. Yoo, I. Kim, S. Kim, C. H. Hahn, C. Lee, and S. Cho, "Effects of annealing temperature and method on structural and optical properties of $\mathrm{TiO}_{2}$ films prepared by RF magnetron sputtering at room temperature," Applied Surface Science, vol. 253, no. 8, pp. 3888-3892, 2007.

[10] J. Xiong, S. N. Das, S. Kim, J. Lim, H. Choi, and J. M. Myoung, "Photo-induced hydrophilic properties of reactive RF magnetron sputtered $\mathrm{TiO}_{2}$ thin films," Surface and Coatings Technology, vol. 204, no. 21-22, pp. 3436-3442, 2010.

[11] G. D. Wilk, R. M. Wallace, and J. M. Anthony, "High- $\kappa$ gate dielectrics: current status and materials properties considerations," Journal of Applied Physics, vol. 89, no. 10, pp. 5243-5275, 2001.

[12] M. Chandra Sekhar, P. Kondaiah, S. V. J. Chandra, and S. Uthanna, "Substrate temperature influenced physical properties of silicon MOS devices with $\mathrm{TiO}_{2}$ gate dielectric," Surface and Interface Analysis, vol. 44, no. 9, pp. 1299-1304, 2012.

[13] M. Chandra Sekhar, P. Kondaiah, S. V. Jagadeesh Chandra et al., "Effect of substrate bias voltage on the structure, electric and dielectric properties of $\mathrm{TiO}_{2}$ thin films by DC magnetron sputtering," Applied Surface Science, vol. 258, pp. 1789-1796, 2011.

[14] N. Martin, C. Rousselot, C. Savall, and F. Palmino, "Characterizations of titanium oxide films prepared by radio frequency magnetron sputtering," Thin Solid Films, vol. 287, no. 1-2, pp. 154-163, 1996.

[15] S. V. Jagadeesh Chandra, P. Sreedhara Reddy, G. Mohan Rao et al., "Effect of post deposition annealing on the structural, electrical and optical properties of DC magnetron sputtered $\mathrm{Ta}_{2} \mathrm{O}_{5}$ films," Journal Optoelectronics and Advanced Materials, vol. 1, pp. 496-501, 2007.

[16] B. Liu, L. Wen, and X. Zhao, "The photoluminescence spectroscopic study of anatase $\mathrm{TiO}_{2}$ prepared by magnetron sputtering," Materials Chemistry and Physics, vol. 106, no. 2-3, pp. 350-353, 2007.

[17] S. Chakraborty, M. K. Bera, S. Bhattacharya, and C. K. Maiti, "Current conduction mechanism in $\mathrm{TiO}_{2}$ gate dielectrics," Microelectronic Engineering, vol. 81, no. 2-4, pp. 188-193, 2005.

[18] Y. Shen, H. Yu, J. Yao et al., "Investigation on properties of $\mathrm{TiO}_{2}$ thin films deposited at different oxygen pressures," Optics and Laser Technology, vol. 40, no. 3, pp. 550-554, 2008.

[19] T. Ohsaka, "Temperature dependence of the Raman spectrum in anatase $\mathrm{TiO}_{2}$," Journal of the Physical Society of Japan, vol. 48, no. 5, pp. 1661-1668, 1980.

[20] J. C. Campuzano, A. Kaminski, H. Fretwell et al., "Role of angleresolved photoemission in understanding the high temperature superconductors," Journal of Physics and Chemistry of Solids, vol. 62, no. 1-2, pp. 35-39, 2001.

[21] K.-R. Zhu, M.-S. Zhang, Q. Chen, and Z. Yin, "Size and phononconfinement effects on low-frequency Raman mode of anatase $\mathrm{TiO}_{2}$ nanocrystal," Physics Letters A, vol. 340, no. 1-4, pp. 220-227, 2005.
[22] D. Kumar, M. S. Chen, and D. W. Goodman, "Characterization of ultra-thin $\mathrm{TiO}_{2}$ films grown on $\mathrm{Mo}(112)$ ), Thin Solid Films, vol. 515, no. 4, pp. 1475-1479, 2006.

[23] C. H. Heo, S. B. Lee, and J. H. Boo, "Deposition of $\mathrm{TiO}_{2}$ thin films using RF magnetron sputtering method and study of their surface characteristics," Thin Solid Films, vol. 475, no. 1-2, pp. 183-188, 2005.

[24] A. Paskaleva, E. Atanassova, N. Novkovski et al., "Conduction mechanisms in thin rf sputtered $\mathrm{Ta}_{2} \mathrm{O}_{5}$ on $\mathrm{Si}$ and their dependence on $\mathrm{O}_{2}$ annealing," in Proceedings of the 23rd International Conference on Microelectron, vol. 7, p. 755, Nis, Yugoslavia, 2002.

[25] J. X. Fang and D. Lu, Solid State Physics, Shanghai Technology and Science Press, 1980. 

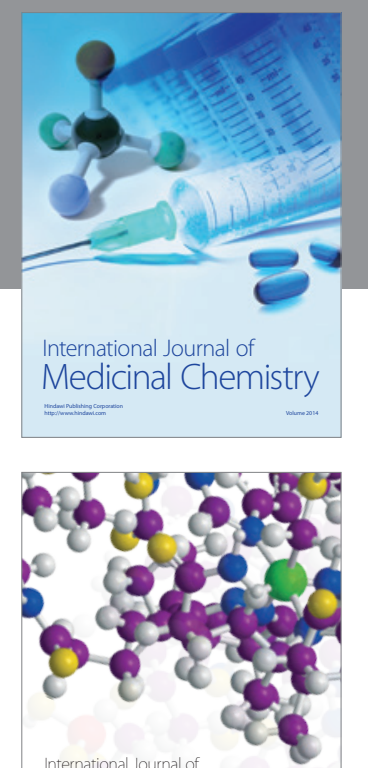

\section{Carbohydrate} Chemistry

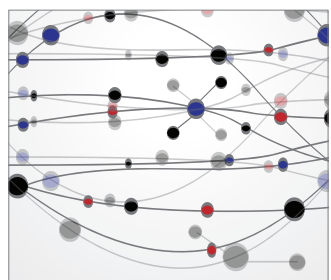

The Scientific World Journal
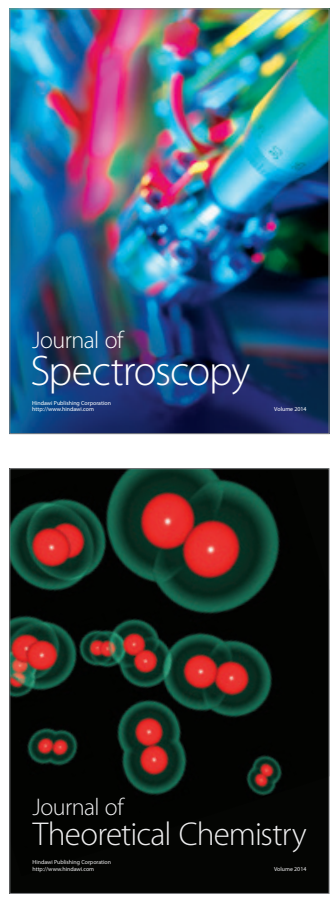
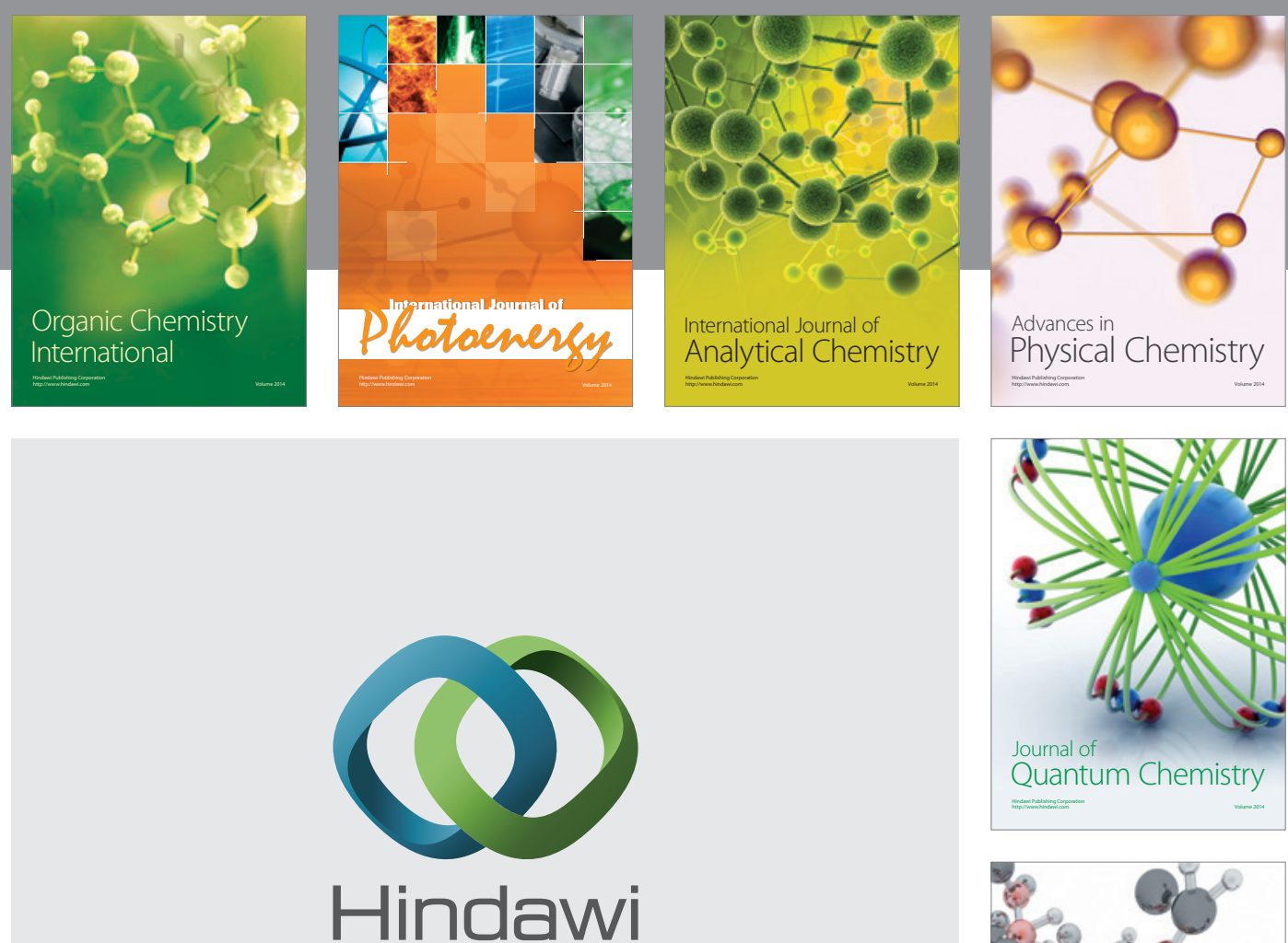

Submit your manuscripts at

http://www.hindawi.com

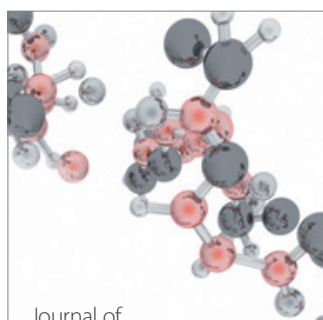

Analytical Methods

in Chemistry

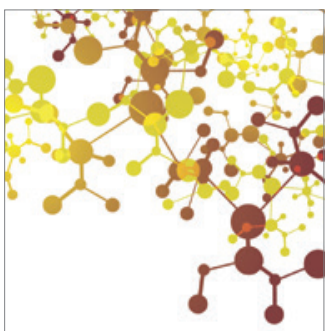

Journal of

Applied Chemistry

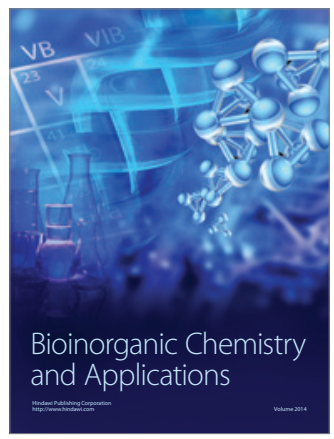

Inorganic Chemistry
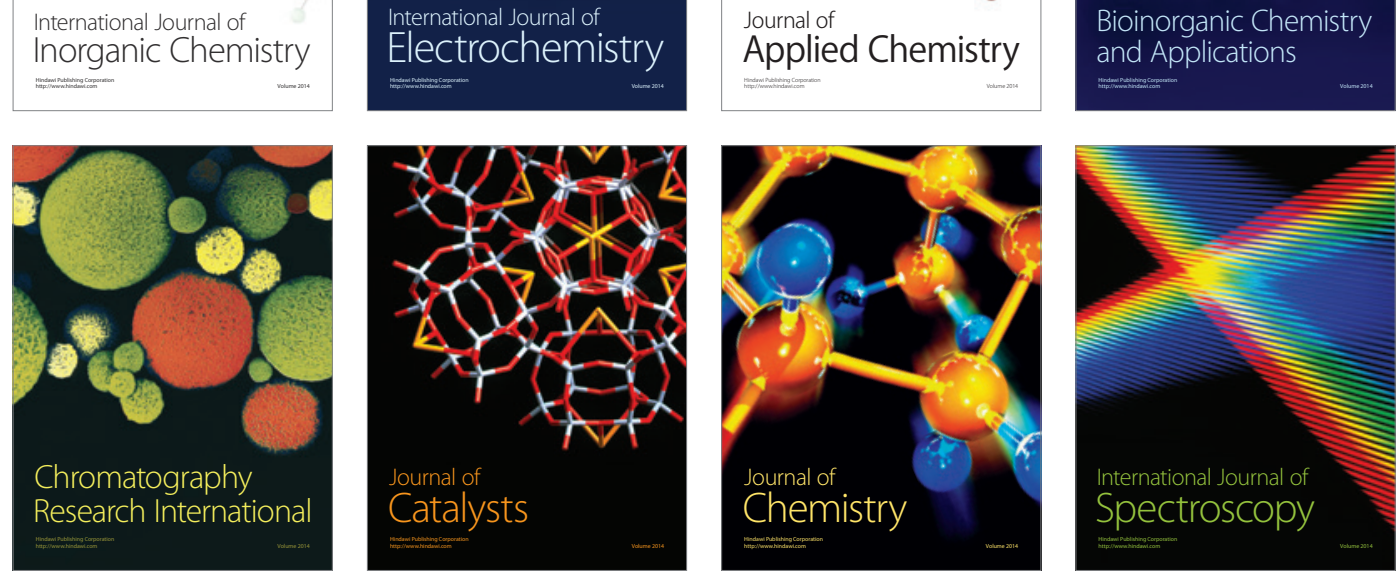